\title{
THERAPEUTIC EFFICACY OF LEVONORGESTREL INTRAUTERINE SYSTEM AS AN ALTERNATIVE TO HYSTERECTOMY FOR MANAGEMENT OF HEAVY MENSTRUAL BLEEDING IN PERIMENOPAUSAL WOMEN
}

\author{
SUDERSHAN DASH ${ }^{1}$, JAGANNATH MISHRA ${ }^{1 *}$, SHASHIS SHANKAR BEHERA ${ }^{1}$, SUBHASHREE ROUT ${ }^{2}$ \\ ${ }^{1}$ Department of Obstetrics and Gynecology, PBMH, KIMS, Bhubaneswar, Odisha, India. ${ }^{2}$ Department of Obstetrics and Gynecology, AIIMS, \\ Bhubaneswar, Odisha, India. Email:shashibehera1971@gmail.com
}

Received: 04 September 2017, Revised and Accepted: 09 December 2017

ABSTRACT

Objective: This prospective observational study has been conducted to find out the efficacy and patient satisfaction of levonorgestrel intrauterine system (LNG-IUS), and it was compared with results of hysterectomy in perimenopausal Indian women with heavy menstrual bleeding (HMB).

Methods: It was a prospective study conducted on 135 cases after taking consent. Patients were inserted with LNG-IUS, and the outcome in terms of further bleeding and quality of life was compared to that of hysterectomy.

Results and Conclusion: Levonogestrol containing-IUS is a highly effective treatment of HMB in perimenopausal women. It is a safe, effective, and quality of life after treatment makes it a good alternative to hysterectomy for HMB.

Keywords: Production of chloroform by fresh water chlorella species and blue green alga Anabaena flos-aquae has also been reported by Wachter and Andelman, 1984.

(C) 2018 The Authors. Published by Innovare Academic Sciences Pvt Ltd. This is an open access article under the CC BY license (http://creativecommons. org/licenses/by/4. 0/) DOIttp://dx.doi.org/10.22159/ajpcr.2018.v11i3.22363

\section{INTRODUCTION}

Heavy menstrual bleeding (HMB) is menstrual blood loss (MBL) that is subjectively considered to be excessive by the woman, defined as prolonged ( $>7$ days) or excessive MBL $\geq 80 \mathrm{ml}$ per menstrual cycle [1] and interferes with her physical, emotional, social, and material quality of life. HMB is an important cause for anemia in perimenopausal women. In general, HMB is a symptom of ovulatory disorders, primary endometrial disorders, fibroid, adenomyosis, and endometriosis, or genital malignancies [2]. Medical treatment for benign lesions includes non-hormonal or hormonal oral medications for a prolonged period of time. When medical treatment is ineffective or unacceptable to the patient, surgical treatment such as hysterectomy or endometrial ablation is the choice. The levonorgestrelreleasing intrauterine system is a nonsurgical, long-acting, and alternative to the traditional medical and surgical treatments for HMB [3].

NICE guideline has stated that while Mirena levonorgestrel intrauterine system (LNG-IUS) is preferable to other medical treatments (tranexamic acid, nonsteroidal anti-inflammatory drugs [NSAIDs], and COC); this recommendation is based on indirect evidence [4].

The effectiveness and cost-effectiveness of levonorgestrel-containing intrauterine system in Primary Care against Standard Treatment for Menorrhagia (ECLIPSE [5]) trial was a pragmatic, multicenter, and randomized trial that compared the clinical effectiveness of the levonorgestrel IUS with that of usual medical treatment in the primary care setting. Indirect comparison has shown that LNG-IUS generates more quality-adjusted life years than other medical treatments (tranexamic acid, NSAIDs, and COCP) and at a lower cost. Therefore, LNG-IUS is the recommended first-line treatment for HMB.

\section{METHODS}

A prospective observational study was conducted to study the efficacy of LNG-IUS in comparison to hysterectomy in perimenopausal women with HMB.

In this study, 135 cases volunteered for taking LNG-IUS.

LNG-IUS was inserted as per guidelines, after excluding cases of fibroid $>5 \mathrm{~cm}$, adnexal mass, submucosal fibroid or polyp and uterine anomaly by hysteroscopy, clinical and suspicious cases of malignancy, any active liver disease, and coagulopathy.

These patients were followed up at 1 month, 3 months, 6 months, and 12-month post-insertion.

Factors observed at follow-up:

1. Number of pads used per day

2. Duration of bleeding

3. Hemoglobin $(\mathrm{Hb} \%)$ level

4. Objective sense of wellbeing.

\section{RESULTS}

Table 1 summarizes majority of cases attending OPD were from age group $15-39$ years (62\%) and $38 \%$ of cases belong to age group $40-$ 45 years. Out of 2165 cases of HMB, 866 cases were found to have no obvious structural pathology, i.e., around $40 \%$ cases.

Out of 537 cases of HMB in perimenopausal group, only 135 (25.14\%) cases gave consent for LNG-IUS insertion, and it was inserted as per guidelines for insertion of LNG-IUS [6].

All cases were using more than 5 pads per day before insertion of LNGIUS

None of the cases were using more than 8 pads per day 1 month after insertion of LNG-IUS while only 28 patients were using 5-8 pads per day, i.e., $78.6 \%$ attained desired MBL after 1 month post-insertion.

Graph 4 shows $89.3 \%$ attained desired MBL after 3 months of LNG-IUS insertion.

While none of the cases were using more than 6 pads per day 6-month post-insertion of LNG-IUS insertion, 90\% achieved desired MBL.

$92 \%$ of the cases achieved desired MBL at 1 year post-insertion of LNGIUS 
Table 1: Demographic characters of total patients (14432)

\begin{tabular}{llllll}
\hline \multirow{2}{*}{ Age in years } & \multicolumn{3}{c}{$\mathbf{n}(\%)$} \\
\cline { 2 - 5 } & HMB (n=2165) & Without obvious pathology (n=866) & Fibroid (n=541) & 0thers (n=758) & Total (n=14432) \\
\hline $15-39$ & $876(40)$ & $329(38)$ & $447(80.2)$ & $224(30)$ & $9048(62)$ \\
$40-45$ & $1289(60)$ & $537(62)$ & $94(19.8)$ & $534(70)$ & $5348(38)$ \\
\hline
\end{tabular}

HMB: Heavy menstrual bleeding

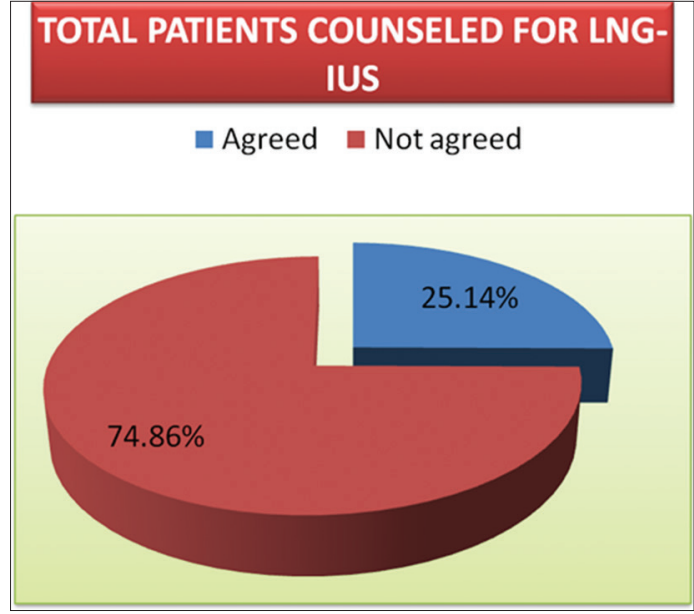

Graph 1: Total patients counseled for insertion of levonorgestrel intrauterine system

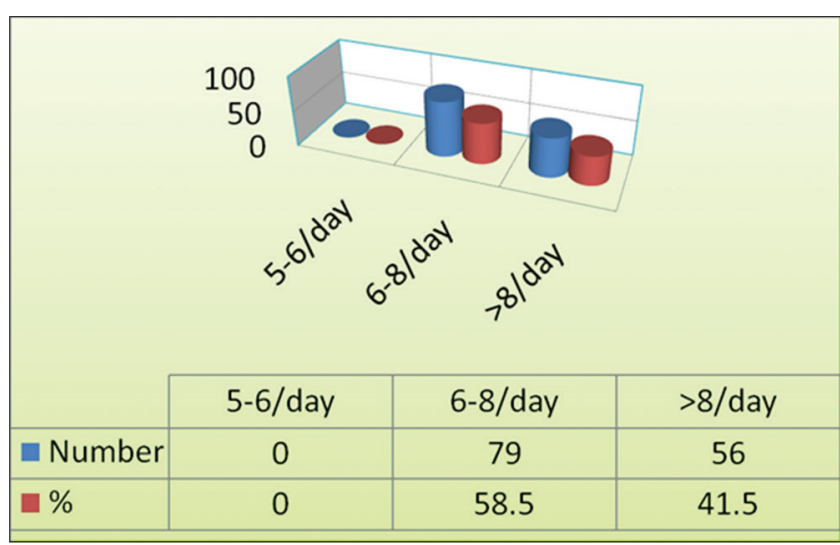

Graph 2: Menstrual blood loss 1 month before insertion of levonorgestrel intrauterine system/hysterectomy

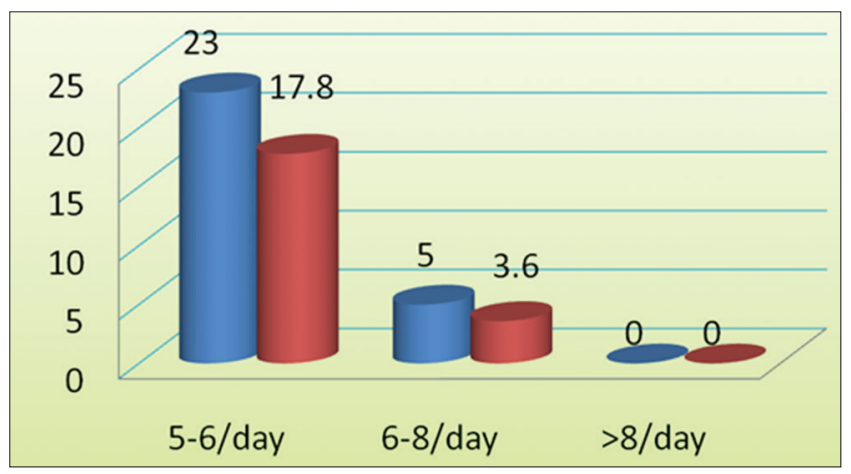

Graph 3: Menstrual blood loss after 1 month of levonorgestrel intrauterine system insertion

All cases were selected for LNG-IUS insertion was anemic. Most (74.3\%) were mildly anemic while $25.7 \%$ were moderately anemic.

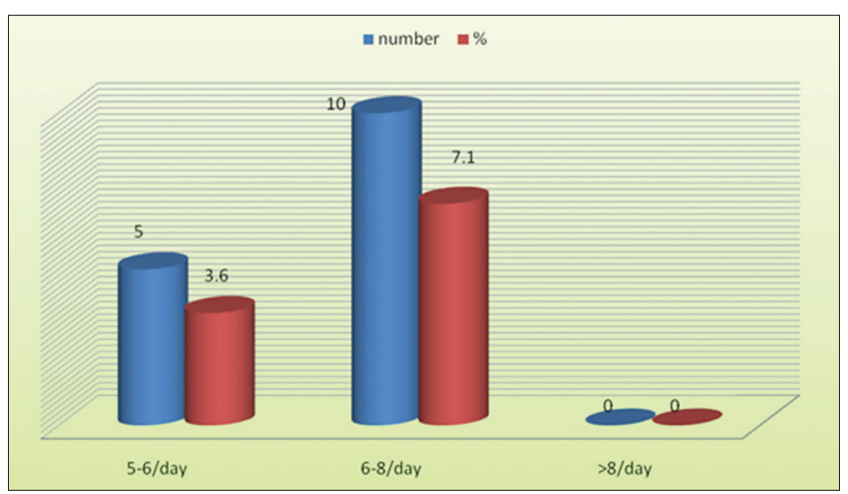

Graph 4: Menstrual blood loss after 3 months of levonorgestrel intrauterine system insertion

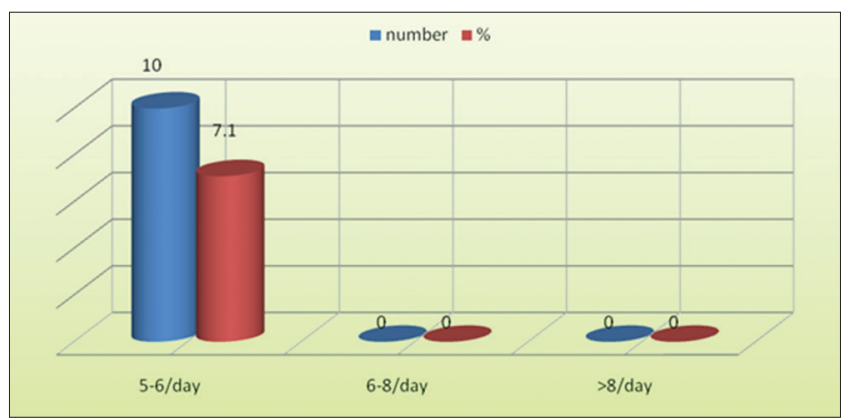

Graph 5: Menstrual blood loss after 6 months of levonorgestrel intrauterine system insertion

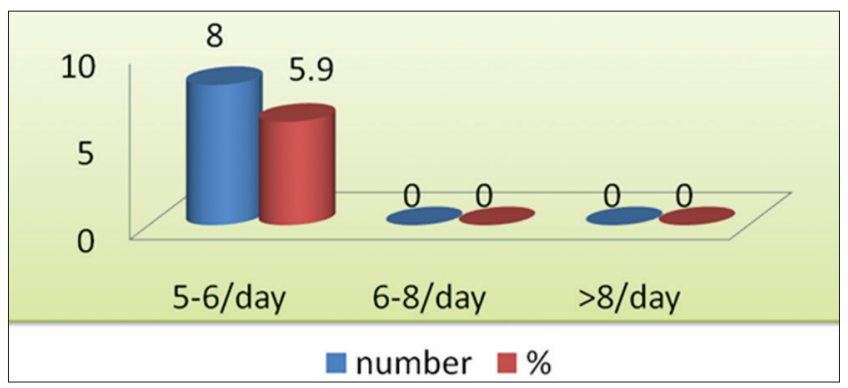

Graph 6: Menstrual blood loss after 1 year of levonorgestrel intrauterine system insertion

Graph 8 shows a continuous increased trend in hemoglobin level after use. $88.2 \%$ achieved hemoglobin level more than $10 \mathrm{~g} / \mathrm{dl}$ after 1 year of use.

Graph 9 shows a continuous increased trend in hemoglobin level after use. 90\% achieved hemoglobin level more than $10 \mathrm{~g} / \mathrm{dl} 1$ year posthysterectomy (Table 2).

Although spotting and intermenstrual bleeding $\mathrm{p} / \mathrm{v}$ were a problem initially for few after 1 year of insertion none of them were having these problems at 1 year. Oligomenorrhea/amenorrhea was seen in 19 cases after 1 year. 


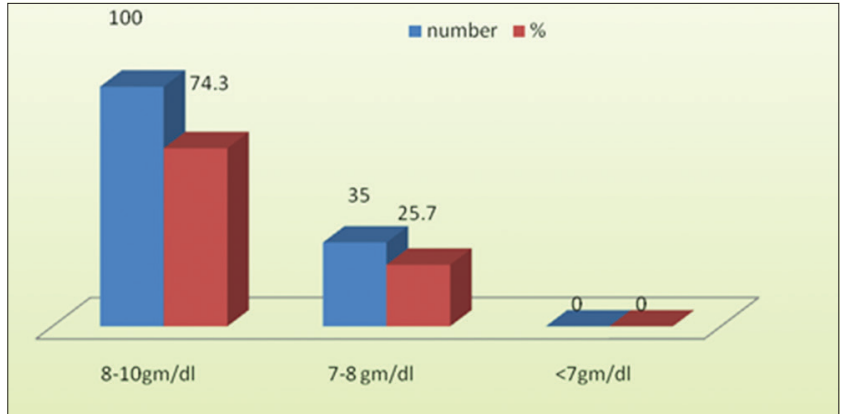

Graph 7: Hemoglobin level before hysterectomy or levonorgestrel intrauterine system insertion

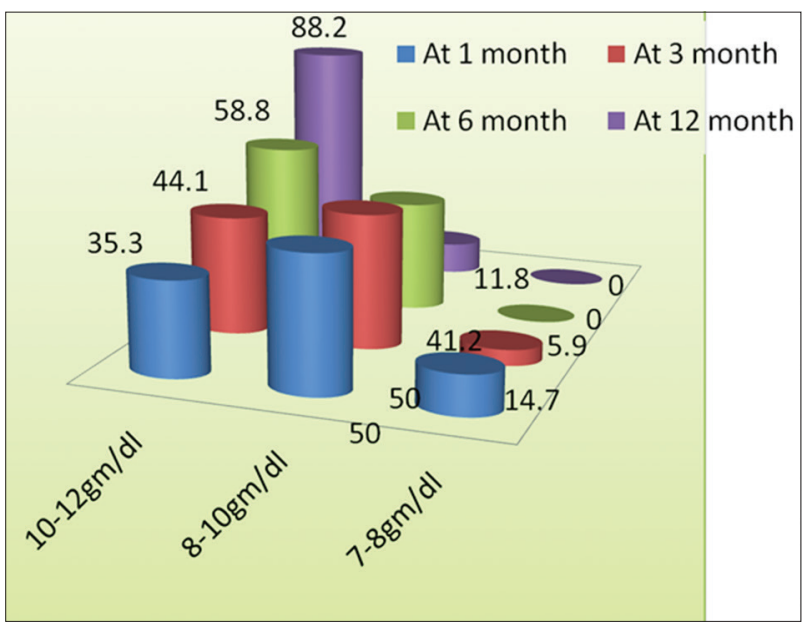

Graph 8: Hemoglobin level at 1, 3, 6, and 12 months postinsertion of levonorgestrel intrauterine system

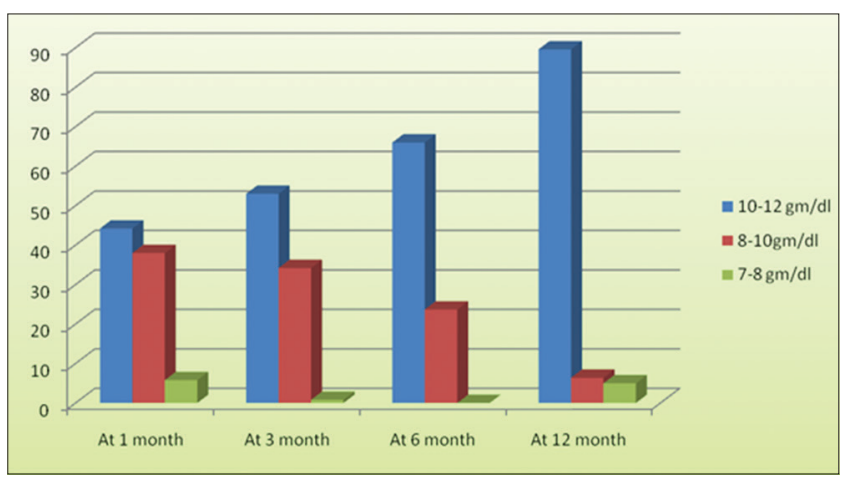

Graph 9: Hemoglobin level at 1, 3, 6, and 12 months posthysterectomy

Pelvic pain and mood changes were seen only in 4 and 2 cases, respectively, and at 1 year $91.9 \%$ cases were satisfied with the procedure. 23 cases did not come for follow-up.

\section{DISCUSSION}

Approximately $30 \%$ of women with perimenopause experience heavy bleeding during menstruation [7]. While in nearly half of all cases no organic pathology is found, a number of risk factors may contribute to the development of HMB [7].

- $60 \%$ of women presenting with complain of HMB were perimenopausal and $41 \%$ were not having any major organic pathology. All cases were using $>5$ pads/day before any procedure.
Table 2: Health-related quality of life after 1 year

\begin{tabular}{lll}
\hline Indicators n (\%) & \multicolumn{2}{c}{$\mathbf{n}(\%)$} \\
\cline { 2 - 3 } & $\begin{array}{l}\text { Following LNG-IUS } \\
\text { insertion (n=112) }\end{array}$ & $\begin{array}{l}\text { Following } \\
\text { hysterectomy (n=156) }\end{array}$ \\
\hline $\begin{array}{l}\text { Spotting } \\
\text { Intermenstrual }\end{array}$ & $0(0)$ & $0(0)$ \\
$\begin{array}{l}\text { bleeding } \\
\text { Oligo/amenorrhea }\end{array}$ & $19(17.7)$ & $0(0)$ \\
$\begin{array}{l}\text { Mood changes } \\
\text { Pelvic pain }\end{array}$ & $2(1.5)$ & $0(0)$ \\
$\begin{array}{l}\text { Content with the } \\
\text { procedure }\end{array}$ & $4(3.3)$ & $0(0)$ \\
\hline
\end{tabular}

LNG-IUS: Levonorgestrel intrauterine system

At 1 month post-insertion $78.6 \%$ cases were using $<5$ pads/day. Irvine et al. found mean MBL of $85.1 \%$ at 1 month post-insertion [8] whereas Tang and Lo [9] found a reduction of 54\% MBL at 1 month.

- At 3 month post-insertion 89.3\% cases achieved normal MBL which is nearer to Anderson and Rybo [10] who found 86\%reduction in MBL but Barrington and Simpkins [11] got only $74 \%$ cases of normal menstruation at 3 months.

- At 6 months and 1 year post-insertion $92.9 \%$ cases achieved normal MBL which is higher than Fedele et al. [12] and Milson et al. who found $80 \%$ and $88 \%$ achieved normal menstruation.

- Hb\% level shows an increased trend both after LNG-IUS and hysterectomy at $1,3,6$, and 12 months without supplementing any hematinic and there was no significant difference between the two $(\mathrm{p}=0.534)$. The same was also noticed by Crosignani et al. [13], Anderson and Rybo [10], and Scholten et al. [14].

- Spotting and intermenstrual bleeding was seen in no case after 1 year though it was a problem in early months.

- Oligo/Amenorrhea was noticed by 19 cases in our study ( $\mathrm{p}=0.035)$

- Pelvic pain was seen in both conditions very rarely.

- Most patients were happy with LNG-IUS except 4 cases out of 112 opt for hysterectomy later due to persistent bleeding.

- In a study by Garg et al. [15] at 6 months post-IUS insertion $10 \%$ had amenorrhea, 40\% had irregular spotting (decreased flow), 23.33\% had infrequent bleeding, $20 \%$ had scanty regular bleeding, and only two women $(6.66 \%)$ had irregular heavy bleeding.

- In the study by Yazbeck et al. [16] 86.1\% women with dysfunctional uterine bleeding were very satisfied with the treatment with LNG-IUS as an alternative to hysterectomy.

\section{CONCLUSION}

There is the high effectiveness of LNG-IUS in the treatment of HMB in perimenopausal women. Significant cases were having oligomenorrhea/amenorrhea after 1 year of LNG-IUS insertion. The patient satisfaction and acceptance were comparable to hysterectomy. It is a safe, effective, and acceptable mode of treatment and can be a good alternative to hysterectomy for HMB due to much benign etiology. A Cochrane meta-analysis of 8 trials comparing medical treatment to all surgical methods found that although endometrial destruction, and especially hysterectomy, more effectively reduces MBL, the LNG-IUS provides an equivalent improvement in the quality of life [17].

\section{REFERENCES}

1. Warner PE, Critchley HO, Lumsden MA, Campbell-Brown M, Douglas A, Murray GD, et al. Menorrhagia I: Measured blood loss, clinical features, and outcome in women with heavy periods: A survey with follow-up data. Am J Obstet Gynecol 2004;190:1216-23.

2. Munro MG, Critchley HO, Broder MS, Fraser IS, FIGO Working Group on Menstrual Disorders. FIGO classification system (PALMCOEIN) for causes of abnormal uterine bleeding in nongravid women of reproductive age. Int J Gynaecol Obstet 2011;113:3-13.

3. Sushil K, Antony ZK, Mohindra V, Kapur A. Therapeutic use of LNG intrauterine system (Mirena) for menorrhagia due to benign lesions-an 
alternative to hysterectomy? J Obstet Gynecol India 2005;55:541-3.

4. Royal College of Obstetricians and Gynaecologists. National Collaborating Centre for Women's and Children's Health. Heavy menstrual bleeding. London: Royal College of Obstetricians and Gynaecologists; 2007 (Guideline CG44).

5. Health Technology Assessment No. 19.88. on Behalf of the ECLIPSE Collaborative Group. Southampton (UK): NIHR Journals Library; 2015.

6. David A, Grinces, Parker K, Jones. A clinical guide to LNG-IUS uses Philadelphia: Lippincott Williams \& Wilkins; 2001.

7. El-Hemaidi I, Gharaibeh A, Shehata H. Menorrhagia and bleeding disorders. Curr Opin Obstet Gynecol 2007;19:513-20.

8. Irvine GA, Campbell-Brown MB, Lumsden MA, Heikkilä A, Walker JJ, Cameron IT, et al. Randomised comparative trial of the levonorgestrel intrauterine system and norethisterone for treatment of idiopathic menorrhagia. Br J Obstet Gynaecol 1998; 105:592-8.

9. Tang GW, Lo SS. Levonorgestrel intrauterine device in the treatment of menorrhagia in chinese women: Efficacy versus acceptability. Contraception 1995;51:231-5.

10. Andersson JK, Rybo G. Levonorgestrel-releasing intrauterine device in the treatment of menorrhagia. Br J Obstet Gynaecol 1990;97:690-4.
11. Barrington JW, Simpkins P. The LNG-IUS for management of menorrhagia. BJOG Int J Obst Gynaecol 1997;104:614-6.

12. Fedele L, Bianchi S, Raffaelli R, Portuese A, Dorta M. Treatment of adenomyosis-associated menorrhagia with a levonorgestrel-releasing intrauterine device. Fertil Steril 1997;68:426-9.

13. Crosignani PG, Vercellini P, Mosconi P, Oldani S, Cortesi I, De Giorgi $\mathrm{O}$, et al. Levonorgestrel-releasing intrauterine device versus hysteroscopic endometrial resection in the treatment of dysfunctional uterine bleeding. Obstet Gynecol 1997;90:257-63.

14. Scholten PC, Christaens GC, Haspel AA. Treatment of menorrhagia by LNG-IUS. Clininal Performance and Impact on Menstruation. Netherlands: Uterecht University Hospital; 1989. p. 47-55.

15. Garg S, Soni A. A Non- surgical lifeline for Abnormal uterine bleeding (AUB)-the LNG IUS. Indian J Obstet Gynecol Res 2016;3:23-7.

16. Yazbeck C, Omnes S, Lavenu VM, Madelenat P. Levonorgestrelreleasing intrauterine system in the treatment of dysfunctional uterine bleeding: A French multicenter study. Gynecol Obstet Fertil 2006;34:906-13

17. Marjoribanks J, Lethaby A, Farquhar C. Surgery versus medical therapy for heavy menstrual bleeding. Cochrane Database Syst Rev 2016;1:CD003855 